\title{
The Trend on Usage of ICT Based Modern Library and Information Service Facilities: A Case Study at Wayamba University of Sri Lanka
}

\author{
WM Thusithakumari ${ }^{1}$
}

\begin{abstract}
Technological applications have transformed the roles of academic libraries and they provide "higher-end-support" and play key role reforming education in academic institutions in the blooming information society. The paper will focus particularly on ICT based library service facilities and the usage of those facilities in the library. The objectives of this study were to identify the usage of the modern facilities of the main library, to find out the trend of users information seeking behavior in ICT based library facilities and to reveal the major reasons of using ICT based modern facility area of the main library, Wayamba University of Sri Lanka (WUSL). The case study was carried out gathering data on the statistics of the usage of ICT based modern library and information service facilities. The data were collected for the period from 2010 to 2015 as the application of ICT into library service is still in primary stage. The study found that the usage of modern facility area has gone up significantly more than the latter part of the period. The undergraduate students' trend was to access the modern facilities in the library as the way of building bridges for fulfilling their information needs. The usage of the library has recognized the ICT as fast information generated source. So, the existing space should be expanded and increased number of access points with infrastructure facilities for activating expected targets. In addition to that the library must move and focus by creating good relationship with user community and adopt information management skills in order to provide sustainable library and information services to achieve academic mission of the university.
\end{abstract}

Keywords: Academic Libraries, Dissemination Information, Information Resources, Information Services, Information Technology, Innovative Practices, Library Services

\footnotetext{
${ }^{1}$ Senior Assistant Librarian, Wayamba University of Sri Lanka, Email: thusitha@mkd.wyb.ac.lk

(iD) http://orcid.org/0000-0002-5735-8797 


\section{Introduction}

A strong situational change in the principles of Library and Information Centers in this exploration of universal knowledge can be seen today. The tremendous amount of information is being generated and transmitted all over the world in various forms, such as printed and electronic materials. After decade's development, the libraries were facing the challenges, how they cater and fulfill the demand and need in minimum span of time. The way of solving the problem was to adopt the Information Communication Technology (ICT) base product and services.

The significant developments in technology application to the library operations are changing continuously the way of information retrieving, in evaluating and disseminating. Therefore the role of library is to acts as facilitator to provide the right information to the right user at the right time (Ranganathan, 1961). Library services providing its users, ICT has been considered as the most important factor for the change in each library operational work. With the globe developing rapidly into a world centering on knowledge, digitization, network and information, the university library is faced with more and more challenges. (Jing \& Jin, 2009)

Owing to the ICT the mission and goals of the library remain unaltered. General or traditional library services have been affected by the introduction of innovative practices because of the new ways of ICT applied for storage and dissemination of information. The new information environment and changes in demand are eager in the university library to review its role and functions, to carryout path selection, mode innovation scientific management and scenario planning (Jing \& Jin, 2009)

On the other hand, adopting ICT for library operations is an ongoing process. Sri Lankan university libraries applying ICT for the management and daily activities, thus library professionals are exposed to different offshoots. The recent addition to the library service providing its users the ICT has been considered as the most important factor for the change in each library operational work although the mission and goals of the library remain unaltered. General or traditional library services have been affected by the introduction of innovative practices because of the new ways of ICT in 
combination with changes in organizational structure and methods of working.

The ICT product and services melt the physical walls or virtual library (Pervez, 2011). Further, Pervez defines the ICT; as "All kind of electronic systems used for broadcasting, Tele Communication and mediated communications" with examples.

In 2007 Jeevan explores the users visit libraries to borrow needed document or to take photocopies/ printouts of these documents form reference collection. The advent of web-enabled information resources, such as; ejournals, e-books and e-reference sources and their access through networks has taken the library to users and a significant amount of information access is now taking place beyond the four walls the library (Jeevan, 2007).

Yapa revealed the overall scenario use of ICT in Sri Lanka and especially in libraries. Author argues that, National Information Policy and National Information Infrastructure are most important things, if a country would like to treat the IT to its benefit. He highlighted in his study that the collaboration work of few Sri Lankan library professionals as a dedicated team they could be able to progress the Library Automation in Sri Lanka. Library consortia in Sri Lanka function with the initiative of the library professionals with minimal administrative and financial support from the authorities (Yapa, 2003).

The study of Cholin is focused on given an overview of Information Technology implementation in different university libraries in India that provides effective access to existing information resources within universities and elsewhere. Further the researcher discussed the role of the INFLIBNET Centre in the overall development of the university libraries through UGC-Infonet E-Journals Consortium (Cholin, 2005).

Antherjanam and Sheeja carried out a study to find out the impact of ICT on LIS and its major shifts and practices in university library of Chichin University of Science and Technology (CUSAT). The major findings of the study were; (a) Users are making very good use of the available ICT facilities. Some of the services were provided faster than before. They are 
answering reference queries With the help of telephone, e-mail, Fax , Selective Dissemination Information and Current Awareness services, finding books through OPAC, Circulation, Book selection, price checking are also done very efficiently using ICT.(Antherjanam \& Sheeja, 2008).

In the present study an attempt has been made to highlight the innovative practices adopted in the delivery of the services at main library, Wayamba University of Sri Lanka.

Wayamba University has four (04) faculties and two (02) Libraries at two premises of the University support the student and staff in their studies, research and other academic activities. The Wayamba University main library serves two faculties of Business Studies and Finance and Applied Sciences in Kuliyapitiya Premises. The collection of the library is growing steadily both in the form of conventional and nonconventional materials. As on 31 December 2015 the collection of the main library was 38135 including books and Audio visuals (CDs \& VCDs). The university academic staff, research scholars, undergraduate students, postgraduate students, administrative and non-academic staff of the university is the regular members of the library. By the December 2015 there were 1994 users and 1635 out of them were undergraduates. At present the Wayamba University library system applies ICT for the library services.

\section{ICT facilities and e-Zone of the library}

e-Zone of the main library Wayamba University of Sri Lanka was established in year 2009 and it has been functioning properly since year 2010. There are 20 Personal Computers (PCs) reserved for users. The electronic information materials; Compact disks (CDs), Digital Versatile Disks (DVDs) etc. are arranged in the e-Zone. Then the users may have used those electronic materials using multimedia. Wayamba University Library Network (WULN) subscribes three (3) databases named; Emerald, AGORA and Food \& Nutrition Bulletin. The Main Library users use only the Emerald Database from 2010 to 2013. From 2014 Wayamba university library users have been provided more online database access facilities with Emerald (Wiley Online, Oxford University Press, SAGE Research Methods) through UGC CONSAL (Consortium of Sri Lankan Academic Libraries provided by University Grants Commission of Sri Lanka). In addition all library users can 
use the e-Zone of the library for their assignment preparations and information searching facilities etc.

The library initiated its automation process in 2005. The library Automated Catalogue - OPAC (Online Public Access Catalogue) is being completed using Open Source Software KOHA. Further, the innovative practices have been introduced in the dissemination information services by the library. Such practices could be summarized in the following ways;

- $\quad$ Easy access to OPAC (Online Public Access Catalogue)

- $\quad$ Conducting User Awareness Programmes

- $\quad$ Easy downloads from subscribed database and some databases provided by UGC CONSAL

- Internet facilities for connecting with global information services

- $\quad$ Easy document delivery from e-journals through e-mail

- Supporting towards promoting e-learning as well as e-information literacy among the scholars

- Automated Circulation

- Assistance from the professionals to the e- resources made available through Information networks

(AGRINET- Agricultural Information Network and SLSTINETSri Lanka Science and Technology Information Network)

- $\quad$ Assistance to Online Inter Library Loan (ILL) requests

\section{Objectives}

There were two major objectives of this study;

1. To investigate the usage of the e- Zone of the main library, Wayamba University of Sri Lanka in Academic Year wise and Faculty wise.

2. To find out the trend on usage of e-Zone and ICT based modern library and Information service facilities.

3 To identify the purposes of using e-Zone of the main library by undergraduate students. 


\section{Methodology}

A survey was carried out gathering data on the recorded statistics of the usage of ICT facilities and the statistics of the usage of e-Zone. Data analysis was done by using MS-Excel. Though the application of ICT into library services has a short period, only the recorded data of initial six years (from 2010-2015) were used. This paper discusses only the trend of the usage of eZone and ICT based modern library facilities from 2010 to 2015.

\section{Findings}

\section{Usage of the e- zone of the Main Library -Annually from 2010 to 2015}

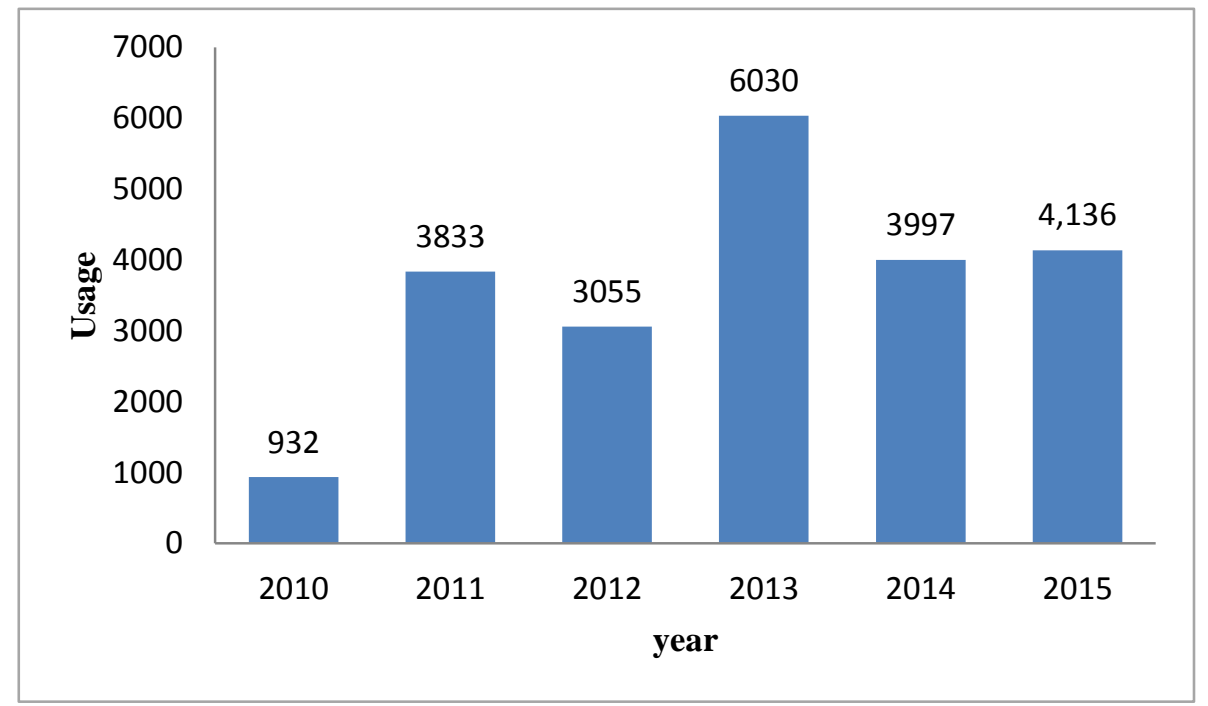

Figure 1: Usage of the e-Zone of the Main Library- Annually from 2010 - 2016

The e-Zone has been promoted through the Used Education Programmes since year 2010. It can be seen the usage of e-Zone is gradually gone up. By 2011 the usage of e-Zone increased up to 3833 with the widespread knowledge about this. In 2012 the usage is decreased but, But this trend of using e-Zone was re-setup gradually in 2013 by 6030and it was nearly 6 time increment of year 2010. In year 2014 e-Zone usage was 3997 and there is a decrease in the e-Zone usage compared to the year 2013. The reasons for the less usage of year 2012 was the Trade Union Actions (TUA) of university academic staff and the new intake of year 2011 were not allocated time for the Library Orientation by the faculty of Business Studies and Finance (BSF). Due to that they were not aware the existing library services and facilities. By 2014, the university allocated more computers and expanded 
the ICT Centre parallel to the "DayataKirula" National Programme. Therefore year 2014 also the usage of e-Zone was decreased but, the figure 1 shows an increment than the period of year 2010 - 2012. And the main reason is university receiving more database access facilities through the UGC Consortium of Sri Lankan Academic Libraries (CONSAL) and users were able to more access for more e- resources from their own places in the university premises and the users aware the seeking information effectively for their needs, then they searching information themselves though in 2014 the e-Zone usage is decreased. In year 2015 also no any steady growth illustrated in the figure 1 .

\section{Faculty wise e-Zone Usage according to the Academic Year}

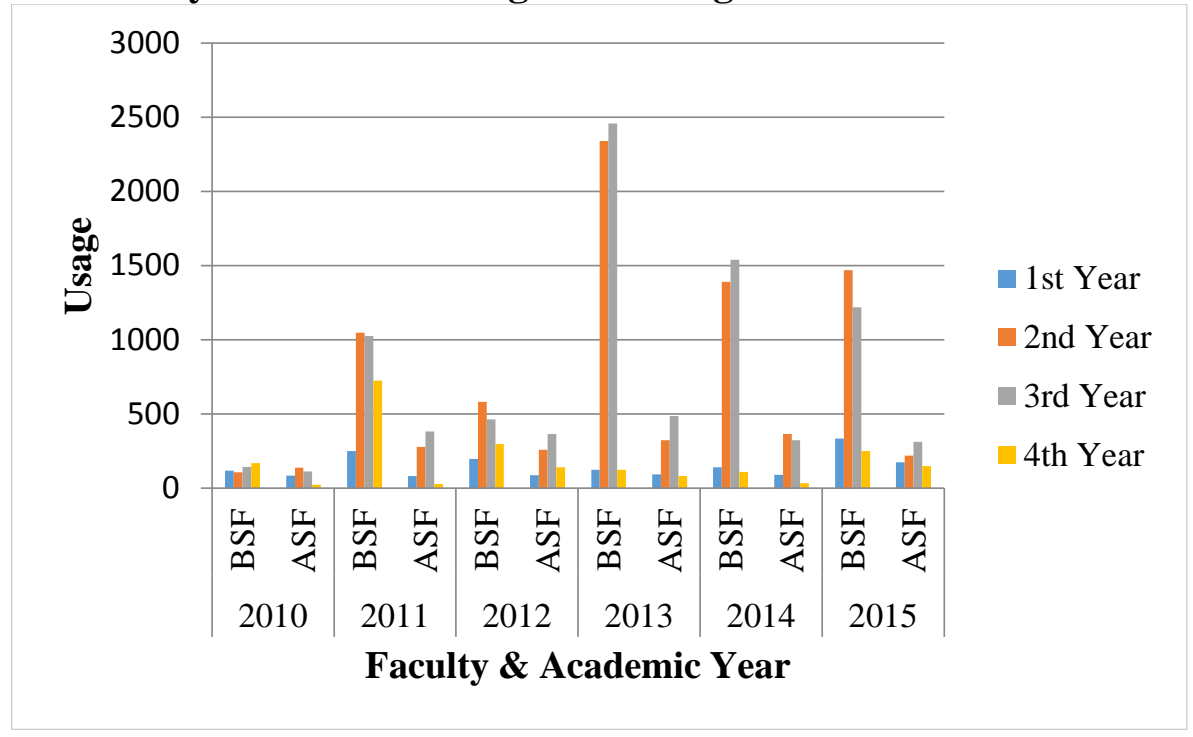

Figure 2: Faculty wise e-Zone Usage according to the Academic Year

The figure 2 illustrates that a clear picture of the usage of e-Zone faculty wise. It can be seen that the initial stage of using e-Zone in year 2010 is similar to each faculty. There are up and downs can be seen in the e-Zone usage of faculty of BSF. But the figure reveals that $2^{\text {nd }}$ and $3^{\text {rd }}$ year undergraduate students' e-Zone usage is significantly higher than other academic years in each year. During this period $(2010$ - 2015) the figure 2 shows that a considerable percentage of faculty of BSF users were also used the e-Zone with limited computer facilities in the e-Zone of the main library. 
The e-Zone usage of the undergraduate students of the Faculty of Applied Science usage is very low against the usage of BSF students.

\section{The trend on usage of e-Zone and ICT based modern library and Information service facilities}

The visual impression of figure 3 below reveals that the usage of e-Zone of the faculty of BSF undergraduate students is increased than that of the students of faculty of Applied Sciences (AS). And also it shows that a gap between the uses of ICT based library facilities of two faculties. It can be observed that BSF students participation for using ICT base library facilities rapidly increase by the mid of year 2012. At the end of year 2011 the Library Orientation programme was re-designed as "Library Orientation and Information Literacy Skill Development Programme" adding more marketing strategic advancements. Due to this reason most students' trend was to access the e-Zone for fulfilling their information gaps and studying by themselves. Hence the faculty of BSF students mostly interested in using ICT based library facilities and they pay good attention to electronic resources for seeking information in the library and ICT helps them to better informed and study ahead. It clearly shows that highest participation value in year 2013.

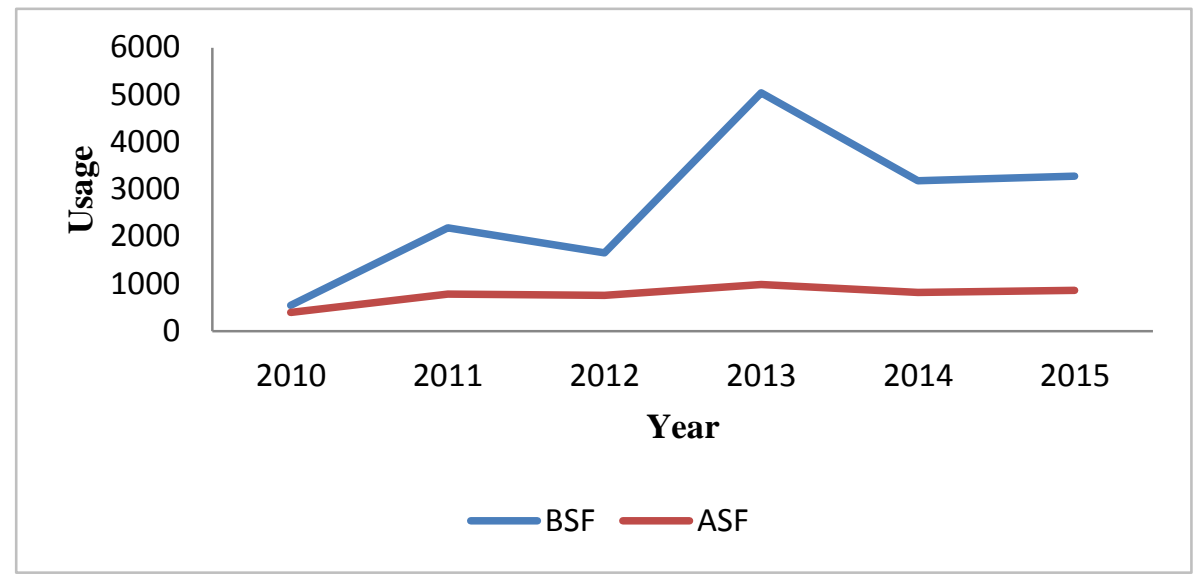

Figure 3: The trend on usage of e-Zone and ICT based modern library and Information service facilities

Comparing with the faculty of AS students' interest in using ICT based modern library facilities are lower than BSF students' interest. The reason might be the long distance between library and the faculty of AS. The usage 
of e-Zone and ICT base modern Library and Information Service facilities of the faculty of AS is steady and no any growth. The users who are regular users of variety of electronic technologies have the necessity refer to the library e-Zone. Faculty of AS building is located far from the library building as well as the hostels. Therefore, it cannot be expected an increment of their participation for using the e-Zone and ICT based modern library facilities. Again in year 2014, the trend of the usage of ICT based library facilities gone down, it highly affected the infrastructure development of other computer labs of the university and all students of the university has been extended more access opportunities to use ICT based modern library service facilities within the university premises.

\section{Purposes of using e-Zone of the main library}

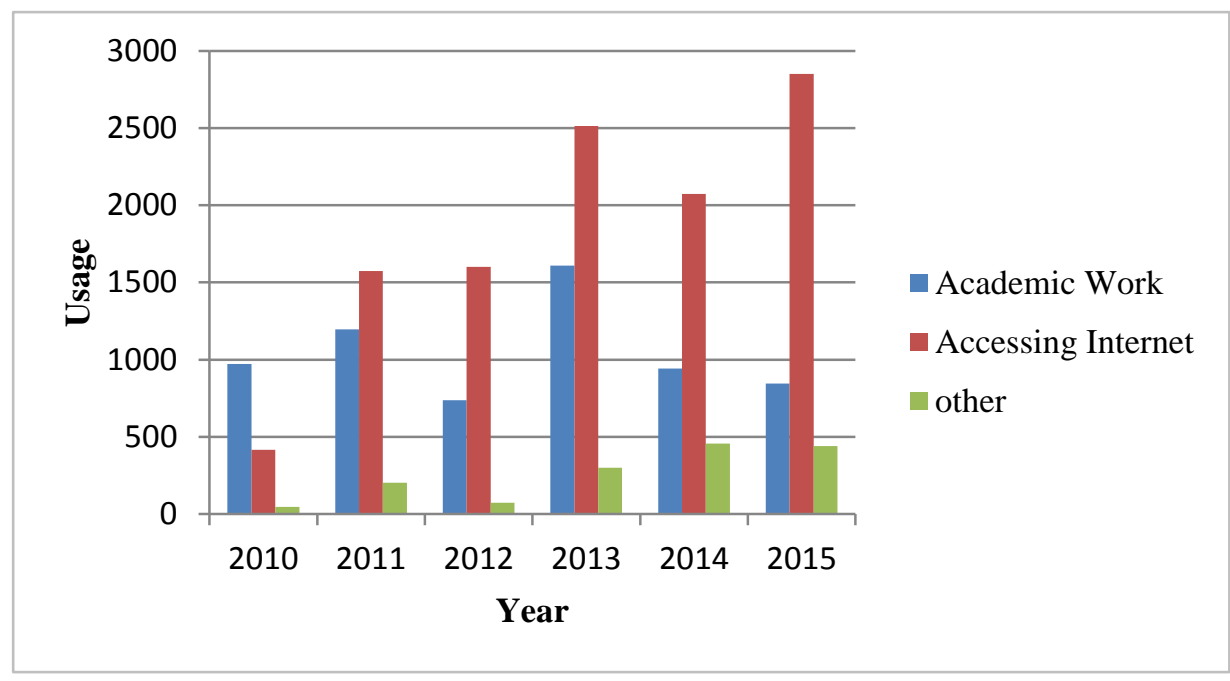

Figure 4: Purposes of using e-Zone of the main library

This figure gives clear idea about the users' purposes of using the e-Zone of the library. This was recorded with the undergraduates' Views/ opinions of using e-Zone. There are three (03) purposes indicated in the e-Zone usage form of the library. It can be observed that there is an increase on purposes of accessing internet from 2010 to 2015. While analyzing the growth trend of Accessing internet, it is observed that the range of number of internet access users per year during the period under study between $417-2851$. Access to the internet growth rate is the highest purpose of using the e-Zone. Here "Access internet" is defined as checking e-mail, electronic communication, 
use of You Tube, social media, accessing Open Access Journals and data bases, Library OPAC and e-journal through CONSAL (Consortium of Sri Lankan Academic Libraries). It is also observed that entire library marketing and promoting strategies brought from 2010 to 2015 were effectively used by the users for seeking information through internet. Further they also prefer to use the e-Zone of the library for their Academic work. Here the "Academic Purposes" are defined as the work of computerizing assignments, thesis, reports, proposals and preparation for the Presentations, usage of CDs and DVDs of books etc. Rodriguez (2006) revealed that according to his studies conducted in Venezuelan University, the academic related activities were major purpose of using ICT. And also Mohmood (2009) agreed that $85 \%$ students use ICT for their educational related purposes including conducting research and class assignments etc. The "Other Purposes" are defined as the, usage of other individual CDs and DVDs, independent learning, scanning documents, leisure and entertainment purposes and computerizing other documents which are not related to academic purposes etc.

\section{Conclusion}

Sri Lankan university libraries are changing very fast with the introduction of ICT base products and services in past decade such as; library automation, internet facilities, for connecting with global information, document delivery etc. The Wayamba University Main Library users are shifted very fast from the traditional to modern information seeking behavior. Thus the e-Zone usage is increased regularly within past initial six years despite the sufficient printed materials. The usage of library has recognized ICT as a very useful and fast information generation source and facilities as well as the trend of using ICT based modern libraries. Generally the widespread facilities of electronic information technology have attracted the user community of Wayamba University. Therefore the library professionals have a challenge in promoting usage of ICT in the library and introducing the same for user's information seeking process with the limited space.

\section{Recommendations}

In the light of the findings of the investigations the researcher gives recommendations as follows; 
- Expand the spaces and increase number of Access Points (Personal Computers / PCs) with infrastructure facilities for achieving expected targets.

- Incorporate e -library services with the vision and mission of the university.

- Libraries must be moved and focus by creating good relationship with user community and adopt information Management techniques to the user awareness programmes.

- Subscribe or increase more opportunities to access to Science stream Online databases too through the UGC CONSAL related to the relevant courses of University.

- Plan and re-structure innovative user awareness progammes more attractively.

- Take immediate actions to automate all services in the library so that users' information needs could be fulfilled promptly and without delay.

\section{References}

Antherjanam, S., Sheeja, N. (2008). "Impact of ICTon Library and Information Science: MajorShifts and Practices in CUSAT Central Library”. pp. 35.43, In 6th International CALIBER-2008.University of Allahabad: Allahabad,

Chisenge, J. (2004). ICT libraries: an overview and general introduction to ICT in libraries in Africa. Paper presented at INASP ICT workshop, held at Johannesberg, South Africa on 21-23 July 2004. Retrieved from http//www.inasp.info/lsp/ict-workshop-2004/session1-chisenge.ppt, (September 5, 2013).

Cholin, V. (2005) "Study of the Application of Information Technology for Effective Access to Resources in Indian University Libraries." The International Information \& Library Review ,37(3), 189-97.

Jeevan, V.K.J. (2007). Technology enhanced Library services and the librarians Identify crisis in Academic and research libraries of India. Libri, 57, 100-109. 
Jing, Guo, Jin, Chen.(2009). The innovative university library: strategic choice, construction practices and development ideas. Library Management, 30(4-5), 295-308.

Kadli, Jayadev H., Kumber, B. D. (2013). Library Resources, services and information seeking behavior in changing environment: a literature review. Library Philosophy and Practice (e- journal). Paper 951, Retrieved from http//digital commons.unl.edu/libplilprac/ 951, 1-27.

Kelvin, Onoriode Oghenovo, Oghenetega, Ivwighreghweta \& Jackson, Akpojaro (2012). A review of issues in information and communication technology (ICT) planning and implementation in academic libraries in Nigeria. Library HiTech News, 27(8),11-17.

Mahmood, K. (2009). Gender, subject and degree differences in university students' access, use and attitudes towards Information and Communication Technology (ICT). International Journal of Education and Development using Information and Communication Technology (IJEDICT), 5(3), 201-216.

Pervez, Ahamed (2011). Development in library services with the advent of ICT based products and services: a continuous process. International Journal of Digital Library Services, 1(2), 1-9.

Ranganathan,S.R. (1961). Reference service. Bangalore: SaradaRanganathan Endowment.

The use of information and communication technologies (ICTs) in African public library services.(2004). INASP inforbrief 3, Retrieved from http://www.inasinfo, 1-4.

Rodriguez, G.C. (2006). Educative uses of ICT, technological skills and academic performance of the Venezuelan university students: A causal perspective. International Journal of Education and Development using Information and Communication Technology (IJEDICT), 2(4), 28-43.

Yapa, N.U. (2003).Utilization of ICT for LIS with Special Reference to Sri Lanka. In First international CALIBER-2003. Ahamedabad: Ahamedabad Information and Library Network Center. 